\title{
THE TIME BUDGET AND BEHAVIOURAL TRAITS OF YOUNG AND ADULT INDIAN EAGLE OWL BUBO BENGALENSIS (FRANKLIN, 1831) (AVES: STRIGIFORMES: STRIGIDAE) IN AND AROUND A NESTING SITE: A PRELIMINARY REPORT
}

\section{Eric Ramanujam}

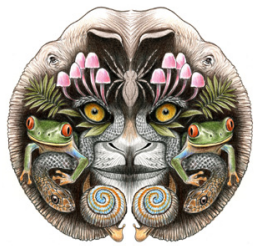

ISSN 0974-7907 (Online) ISSN 0974-7893 (Print)

OPEN ACCESS

Principal Investigator (Faunistics), Pitchandikulam Bioresource Centre / Pitchandikulam Forest Consultants, Auroville, Tamil Nadu 605101, India

ericramanujamowl@yahoo.com

\begin{abstract}
A family of the Indian Eagle Owl Bubo bengalensis was monitored at their nest site at Nanmangalam Reserve Forest on the outskirts of Chennai City from 5 January to 8 March 2011. Various behavioural patterns were identified and the time spent on each activity was noted. All three types of subjects (viz.: breeding male, brooding/incubating female and young) showed different behavioural characteristics. In the breeding female, high intensity activities were incubation, brooding, vigilance and out of sight (construed to be out hunting) and low intensity activities comprised comfort movements, feeding, pellet regurgitation, feeding young, prey delivery and disturbed at the nest. In the young, high intensity activities were resting and moving, while low intensity activities were feeding, pellet regurgitation and wing flapping. In the male, the bulk of time was spent in vigilance and the other high intensity activity was out of sight (construed to be hunting). Low intensity activities included comfort movements and prey delivery. The male hunted more than the female. Forty-five prey items were delivered by the two parents and these items were identified to the species or generic level.
\end{abstract}

Keywords: Behavioural traits, biomass, comfort movements, descriptive approach, ethograms, long-term activities, short-term activities.
Activity profiles, as deduced from time budgeting and behavioural patterns, provide an ethological profile of a species since these are a quantitative description of how animals partition their time in relation to their activities (Kurup \& Kumar 1993; Ramachandran 1998). Patterns of activity can vary widely between species and these activity budgets are fundamental to the study of life histories and ecology of a species (Evers 1994; Hamilton et al. 2002; Jonsson \& Afton 2006). Time activity budgets reflect not only on behavioural aspects but also on individual physical condition, food availability, social structure and environmental conditions (Pauls 1998). Hence, they are the fundamental parameters for understanding the behavioural ecology of a species, which can holistically influence conservation biology. A case in point was the study on the time budget
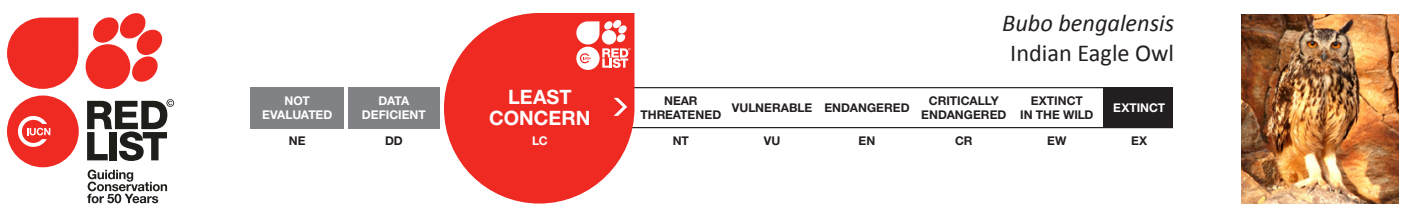

DOI: http://dx.doi.org/10.11609/jott.2429.7.14.8139-8147

Editor: Reuven Yosef, Ben Gurion University of the Negev, Eilat Campus, Israel.

Date of publication: 26 November 2015 (online \& print)

Manuscript details: Ms \# 04266 | Received 24 January 2015 | Final received 14 October 2015 | Finally accepted 26 October 2015

Citation: Ramanujam, M.E. (2015). The time budget and behavioural traits of young and adult Indian Eagle Owl Bubo bengalensis (Franklin, 1831) (Aves: Strigiformes: Strigidae) in and around a nesting site: a preliminary report. Journal of Threatened Taxa 7(14): 8139-8147; http://dx.doi.org/10.11609/jott.2429.7.14.8139-8147

Copyright: (c) Ramanujam 2015. Creative Commons Attribution 4.0 International License. JoTT allows unrestricted use of this article in any medium, reproduction and distribution by providing adequate credit to the authors and the source of publication.

Funding: None

Conflict of Interest: The author declares no competing interests.

Acknowledgements: I wish to thank the Principal Chief Conservator of Forests and Chief Wildlife Warden, and District Forest Officer, Chengalpattu Division for granting us the 'permit for entering into Nanmangalam Reserve Forest and carrying out research' (Order dated 06.12.2010, Ref. No. WL5/53750/2010). I also wish to thank our photographer A. Lakshmikantan for diligently following the owls and photographing them. M. Bubesh Guptha was an enormous help in rendering the statistics and keeping up with my mercurial way of thinking in presenting this article and so was our systems manager P. Karunakaran 
and behavior of the nesting Bald Eagle Haliaeetus leucocephalus, which has had an impact on the protection of nesting sites and curtailment of human activity of pertinent areas during the breeding season (Cain 2010).

Published information on the activity budget of Indian birds is very poor-only a few case studies exist concerning the Pheasant-tailed Jacana Hydrophasianus chirurgus, Bronze-winged Jacana Metopidius indicus (Ramachandran 1998), Southern Crow Pheasant Centropus sinensis (Natarajan 1991), White-breasted Kingfisher Halcyon smyrnensis (Asokan \& Ali 2010), Indian Roller Coracias benghalensis (Sivakumaran \& Thiyagesan 2003) and Indian Myna Acridotheres tristis (Mahabal 1991). Among owls, globally, the only species whose activity budgets have been studied are the Burrowing Owl Athene cunicularia (Haug et al. 1990; Plumpton \& Lutz 1993; Chipman 2006; LaFever et al. 2008) and the Snowy Owl Bubo scandiacus (Sheilds 1969; Krivtsov 1988; Potapov \& Sale 2012). Activity patterns for some nocturnal owls are available (e.g., Bosakowski 1989; Sovern et. al. 1994; Delany \& Grubb 1999) but time budgets were not prioritized. This is contrary to diurnal raptors whose time budgets and activity patterns have been studied in detail (e.g., Fischer 1986; Collopy \& Edwards 1989; Jimenez \& Jasic 1989; Watson et al. 1991;
Aumann 2001; Madders \& Whitfeld 2006).

In this study, I present the time budget and activity pattern of a pair of Indian Eagle Owls and their young both during the day and night.

\section{Material AND MethodS}

Study area: Nanmangalam Reserve Forest (NRF) $\left(12^{\circ} 93^{\prime} \mathrm{N} \& 80^{\circ} 17^{\prime} \mathrm{E}\right)$ is spread over 320.92ha and is cradled by the vast townships of Tambaram, Pallikaranai, Alandur and Velachery on the outskirts of Chennai, Tamil Nadu in southern India (Fig. 1). The vegetation of NRF is described as 'Vandalur scrub'. Hillocks occupy approximately half of the area, predominantly towards the centre. Low lying plains are present along the boundary on both the eastern and western sides and three ponds occur there. In the years 1963-1980, areas were leased out for quarrying rocks. Subsequently, when the Forest Conservation Act came into force, the practice was discontinued. The signs of the quarrying industry are still visible in the form of five deep and steep sided water filled depressions - the nesting areas of Bubo bengalensis (Anonymous 2009).

Methods: Studies on $B$. bengalensis in NRF lasted from December 2010 to November 2011 - a period of one year. On 05 January 2011 a nest scrape with three eggs (Image 1) was located (date of laying

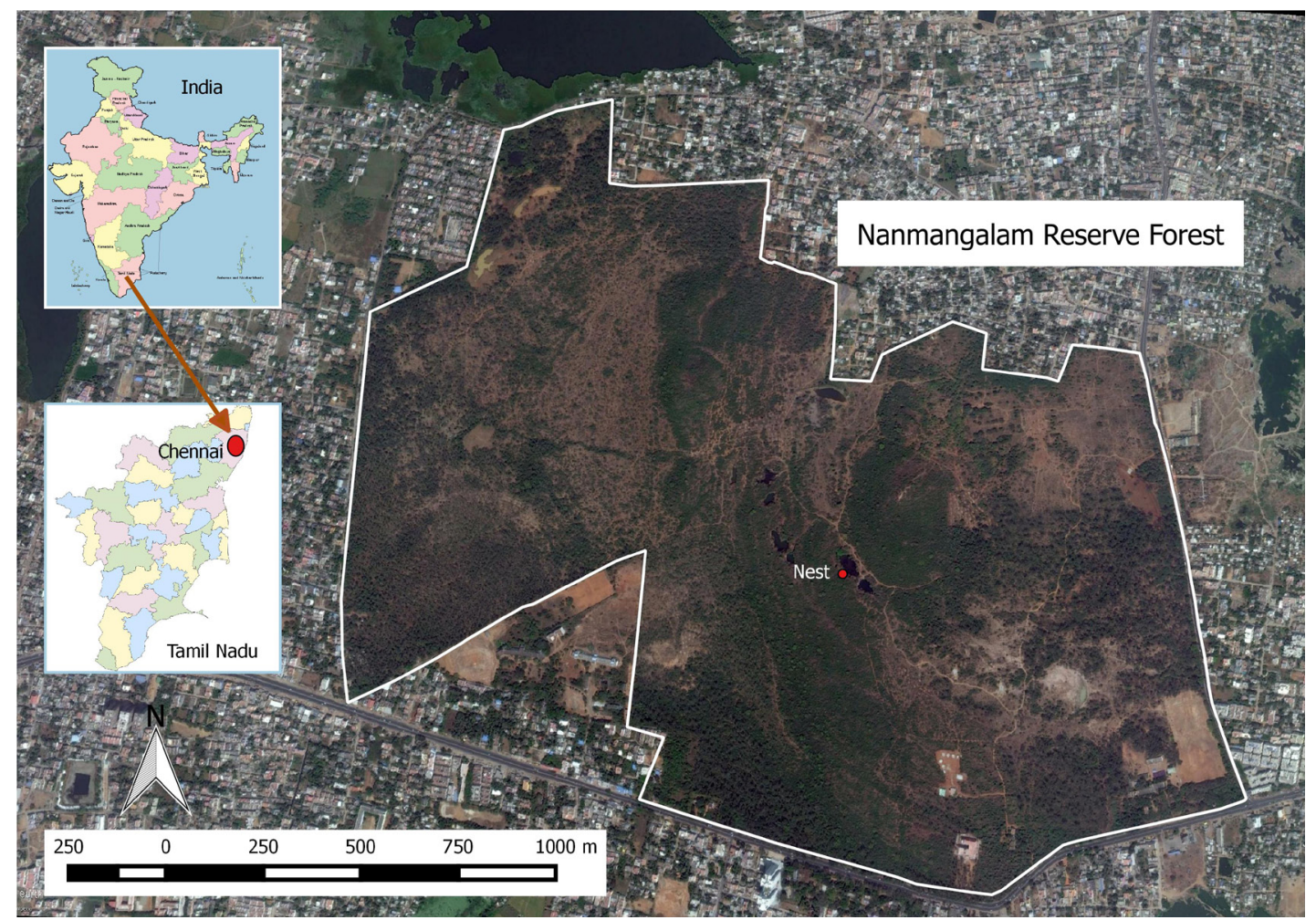

Figure 1. Study area 


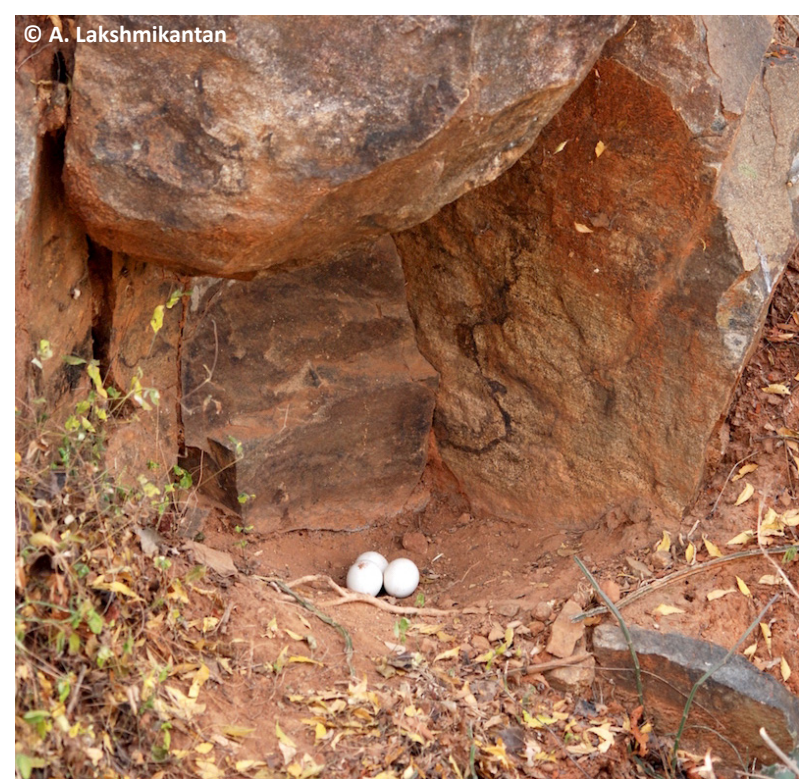

Image 1. Nest scrape with overhang discovered on 05 January 2011.

unknown). This belonged to a single pair of owls that were quite comfortable with humans after having been photographed over many years by members of Pelican Nature Club. This nest and its environs were watched for the next nine and half weeks (up to the middle of the second week of March 2011) on a 24- hour basis twice a week. Our vigil usually began around $16.00 \mathrm{hr}$ and lasted until the same time the next day. Occasionally, due to inability to get to the site on time, we began later but always maintained the 24 hour observation period. By the second week of March, the young had moved away over the lip of the quarry and elsewhere. This made finding and monitoring them and their parents on a regular basis difficult; hence this particular effort was discontinued. Nevertheless, we regularly sighted the owlets even after that period and other less intensive data gathering exercises progressed well on other facets of behavioural ecology of the species in general and these subjects in particular.

Observations were made with binoculars (Olympus Trip Light $10 \times 21$ Roofprism and Spy Net Night Vision Infrared Stealth Binoculars) and a monocular spotting scope (Firefield 5 × 50 Nightfall Night Vision Monocular) with infrared option, which made night monitoring possible. In addition, my field assistant was provided with a Eye Clops night vision infrared goggles. The duration of short-term activities was measured using an electronic stopwatch. Long-term activities were measured by hours / minutes. Behavioural data was pooled at the end of each observation period and the percentage of time spent on each activity by individual birds was deduced. Since we did not know the exact date of hatching and did not have permission to handle any wildlife, the approximate age of the nestlings was inferred using feather morphology/molt patterns (Ramanujam \& Murugavel 2009).

We chose a basic descriptive approach because of the small sample size (one nest and five subjects) and not a hypothesis testing approach where investigators have estimated outputs based on many observations and large sample sizes. LaFever et al. (2008) adopted the descriptive approach concerning $A$. cunicularia in spite of a hypothesis testing option ".... because for a non-experimental study of behavior, we expect $a$ priori that there were differences among groups of individuals observed. This follows the recent argument for emphasizing estimation rather than statistical significance of null hypotheses that are trivial and presumably false (Yoccov 1991; Johnson 1999)".

I wish to state that it was impossible to arrive at the exact moment when behaviour of long-term activities was concerned - for example, 'vigilance' and 'out of sight'. We had recorded these in hours/minutes and had to balance them out when filling in the spreadsheet and converting data to seconds. This is the reason why most, if not all authors dealing with activity budgets and time profiles prefer to provide percentage values rather than raw data (see Supplementary file). Here I have provided raw data along with percentages converted from hours and minutes to seconds. Some rounding off had to be resorted to so as to suit the 86,400 seconds that comprise a 24-hour cycle. However, we are convinced that this has led to a very low bias since the values are indicative figures and not absolute.

Another minimal bias resulted from our inability to specifically document the time spent by adult birds in flight. Under normal circumstances flight by the adults was unexpected meaning that the male and female just left their positions suddenly and disappeared from view without any prior warning. When we approached the nest the female flew away and moved from point to point and since we were more concerned with documenting the young we could not keep track of timing the flight sequence. Hence, in the first circumstance, the period of flight has been accommodated under 'out of sight' and in the second accommodated under 'disturbed at nest'.

In the process of documenting the time budget and behavioural traits of the subjects, direct observation enabled us to identify most prey items delivered by the adults to the nest and the young in the vicinity of the nest. We have tried our best to specifically identify the 
prey items. Biomass was calculated as the mean value of 10 individuals of each species/group undergoing study on another project that deals with population dynamics of non-volant small mammals. Biomass was chosen as the principal measure of classification of prey as it has a more direct nutritional interpretation instead of quantitative measures (Reinecke 1979). The categories of particular components of food consumed were assessed according to a pre-established system in place for calculating trophic connections of owls in India pioneered by Kumar (1985) and followed by others (Verzhutskii \& Ramanujam 2002; Ramanujam \& Verzhutskii 2004; Ramanujam 2006). In this case, three classes were relevant: basic food - prey occurring with a frequency above $20 \%$; constant food - prey occurring with a frequency between 5-20\%; and supplementary food - food occurring with a frequency between 1-5 \%.

\section{RESULTS}

\section{Behavioural traits (Table 1)} In the reproductive female

1. Incubation: When the female was observed incubating the eggs. Sometimes it would rise up a bit and shuffle from side to side which was probably when the eggs were turned over (Image 2).

2. Brooding: When the female was observed with young at the nest (Image 3 ).

3. Vigilance: The female was observed brooding the young from 29 January to 13 February but after that ceased brooding and spent time away from the nest, but in the vicinity of the young.

4. Comfort movements: Stretching and preening.

5. Out of sight of nest region: This was implied to be the time when the female was out of sight to the time it delivered prey to the nest or in the vicinity of the nest.

6. Feeding: As long as the eggs were incubated, the

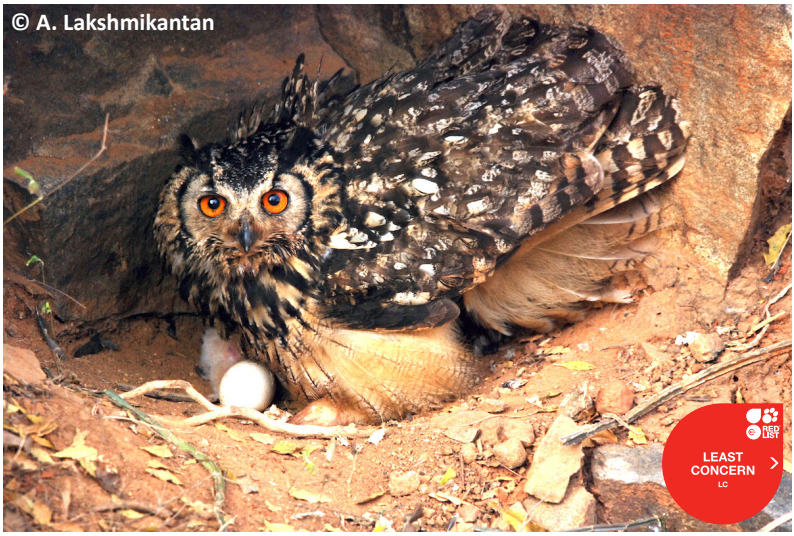

Image 2. Incubating female (22 January 2011). female ate at the nest. When the nestlings were very young the female, in addition to tearing up prey to feed them, also ate portions of prey. After the young became self-sufficient feeders the female did not eat at the nest and presumably, like the male, ate away from it - hence this data is combined under 'out of sight of nest region'.

7. Pellet regurgitation: When regurgitating pellets the female flew to a convenient perch in the vicinity and carried out the necessary motions. But once the young hatched, the female ceased to regurgitate pellets in the vicinity of the nest.

8. Feeding young: The time it took for the female to bring prey and to feed very young chicks. After the young became self-sufficient feeders and began giving loud hunger calls the female handed over the prey beak to beak. In contrast, the male left food for the young on the ground.

9. Prey delivery to young: The female began bringing food for the young quite regularly after they began feeding by themselves at around 16 day post-hatching.

10. Disturbed at nest: Three times we approached the nest whereupon the female flushed but came back as soon as we retreated after taking photographs.

\section{The young}

On 29 January 2011 we found that two chicks had hatched (Image 4) - the larger was referred to as Young 1 and the smaller Young 2. During the next visit on 01 February 2011 the third had also hatched but it was not encountered on our next visit on 05 February 2011. During the first encounter with the third chick it was comatose and stirred very little and since the observation of behaviour did not progress beyond that point the subject has been eliminated from analysis. The two survivors grew well and were observed occupying the nest proper up to 19 February 2011 when they

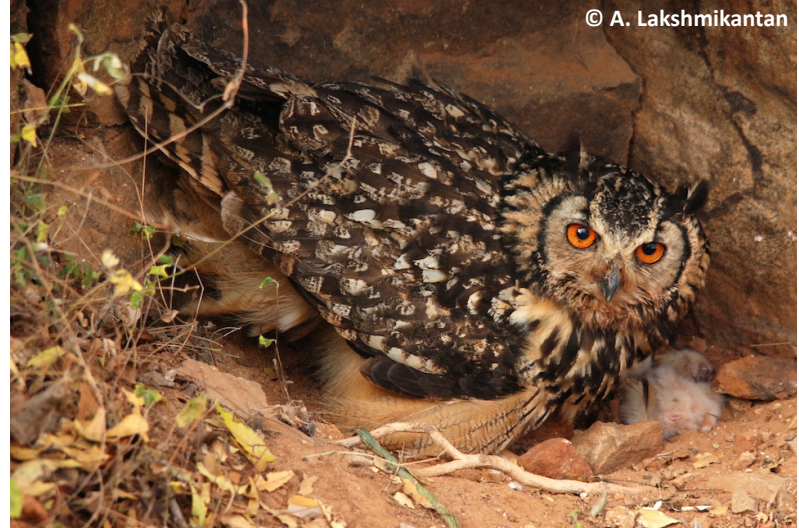

Image 3. Brooding female (29 January 2011). 


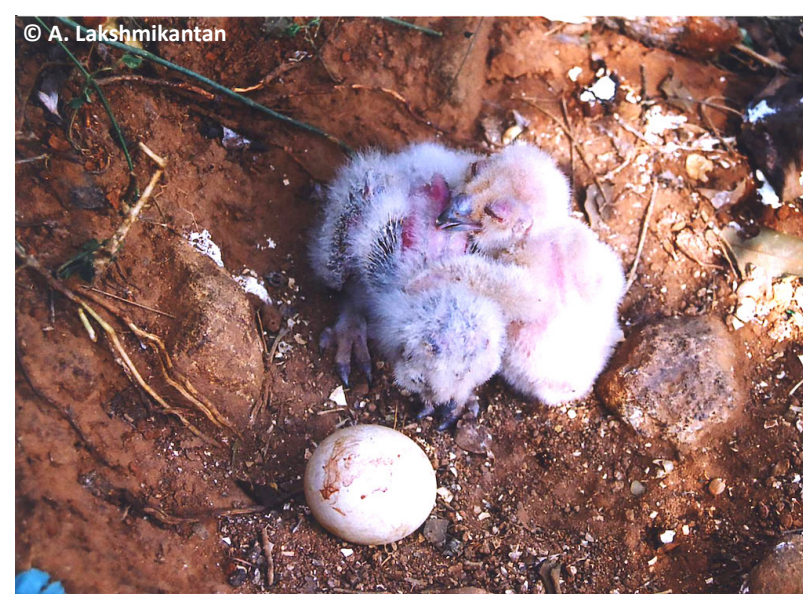

Image 4. Newly hatched chicks (29 January 2011).

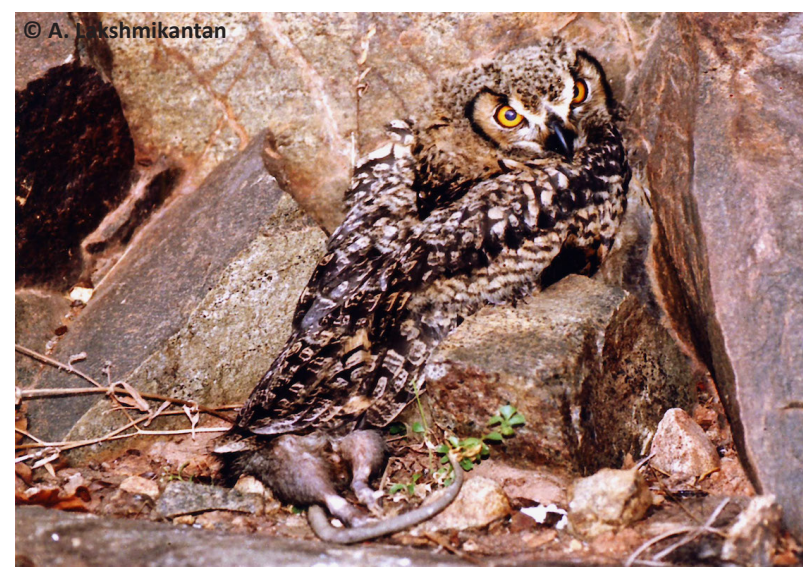

Image 6. 37 day old 'brancher'. The young had separated and this was the last time we could monitor them on a regular basis. An unconsumed Lesser Bandicoot Bandicota bengalensis is visible at the bottom (08 ${ }^{\text {th }}$ March 2011).

would have been around 21 days old. After that they gradually began exploratory movements but returned to the nest. On 23 February 2011 they had abandoned the nest scrape and found away from it but were in the immediate vicinity (Image 5). After that they were found at increasing distances from the nest but still within observable range. The last time they were seen within monitorable range was on 08 February 2011 by which time they had seperated and when they were ca. 37 days old (Image 6).

1) Resting: This was considered to be the time when the young were prostrate or with only the head up. The young panted frequently during the daytime when they were awake since temperatures were high. As they got older they gradually gave up the crouched posture and adopted a very cat-like appearance by resting on their elbows with the tarsus in nearly almost

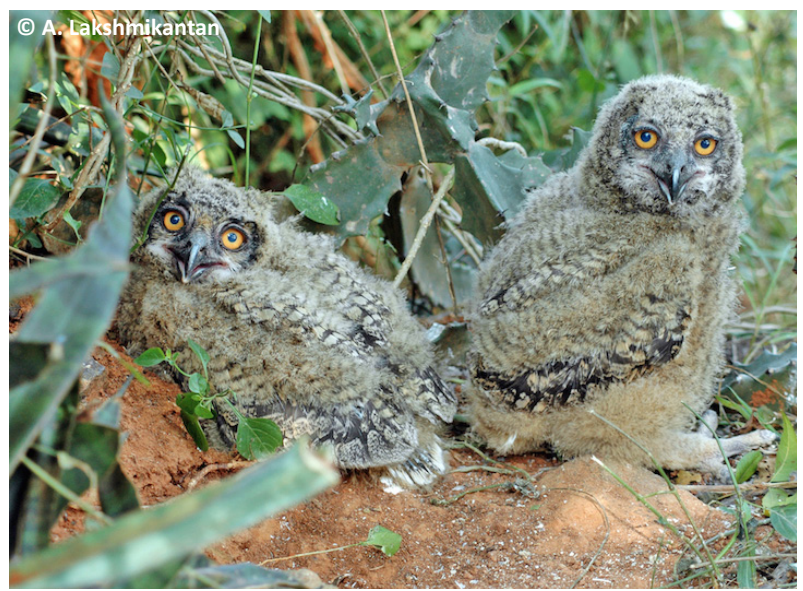

Image 5.26 day old chicks in the vicinity of the nest site but not occupying it (24 February 2011).

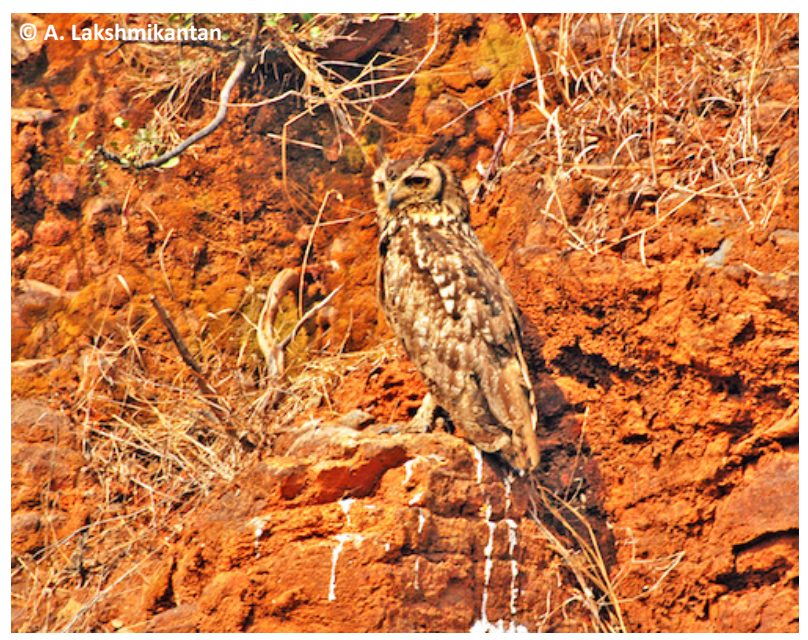

Image 7. Male parent at Vigilance Site 1 . The sleeked concealing plumage is distinctive as are the faeceal markings (09 January 2011).

complete contact with the ground.

2) Moving: From dusk until dawn after the age of 10 days the young were quite active. Activity increased with age and they gradually left the nest site when about 20 days old by which time they could feed independently by themselves.

3) Feeding: The time it took for each of the young to ingest prey, both when the mother fed them and when they fed by themselves. The last time the female was seen to actually feed the young was on the night of $16^{\text {th }}$ February after which it left food within the vicinity. The male was never seen to feed the young and always left prey near them and the female. By the time the young left the nest they were capable of ingesting prey on their own.

4) Pellet regurgitation: The time it took when the young began gaping to the time they ejected pellets. 


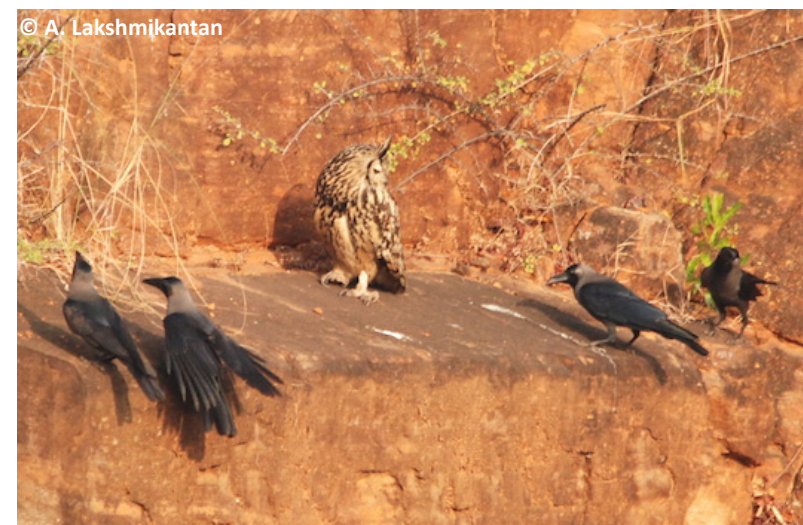

Image 8. Male parent at Vigilance Site 2. Mobbing by House Crows Corvus splendens is obvious (20 January 2011).

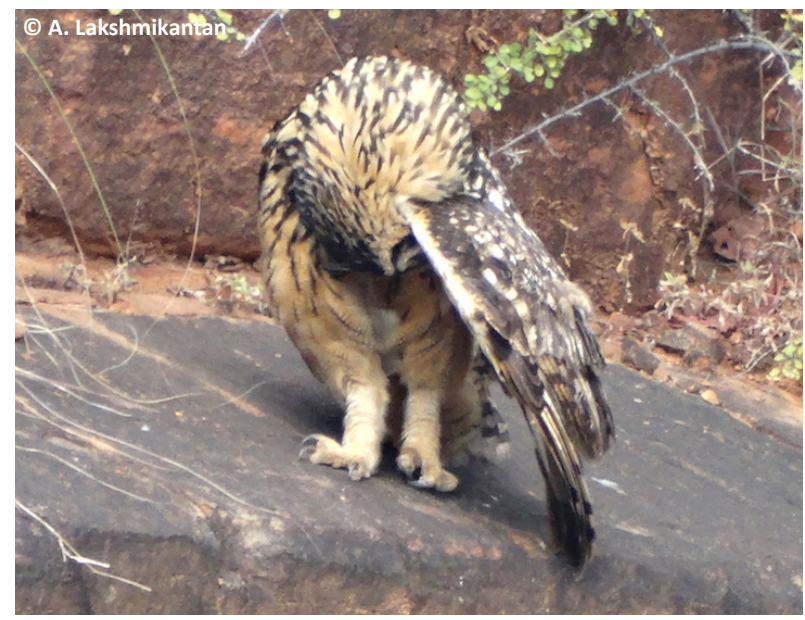

Image 10. Abdominal preening by the male at Vigilance Site 2 (20 January 2011).

5) Flapping: During the evening hours the young spent some time performing flapping exercises, presumably in preparation of flying which is possible only around 58 days (Pande \& Dahanukar 2011).

\section{In the reproductive male}

1) Vigilance: During daylight the male always occupied three perches within sight of the nest (Images 7, 8 and 9). In spite of mild mobbing by crows it was never seen to move away or react (Image 8). From time to time, whenever humans were sighted in the vicinity, it gave the anxiety call - a muffled bark like vocalization. In actual fact it was the key to determine the vicinity of the nesting area simply by observing its behaviour since it showed a marked reluctance to vacate its perch.

2) Comfort movements: Periods of stretching, preening and scratching behaviour (Images 10 and 11).

3) Prey delivery: The time it took for the male

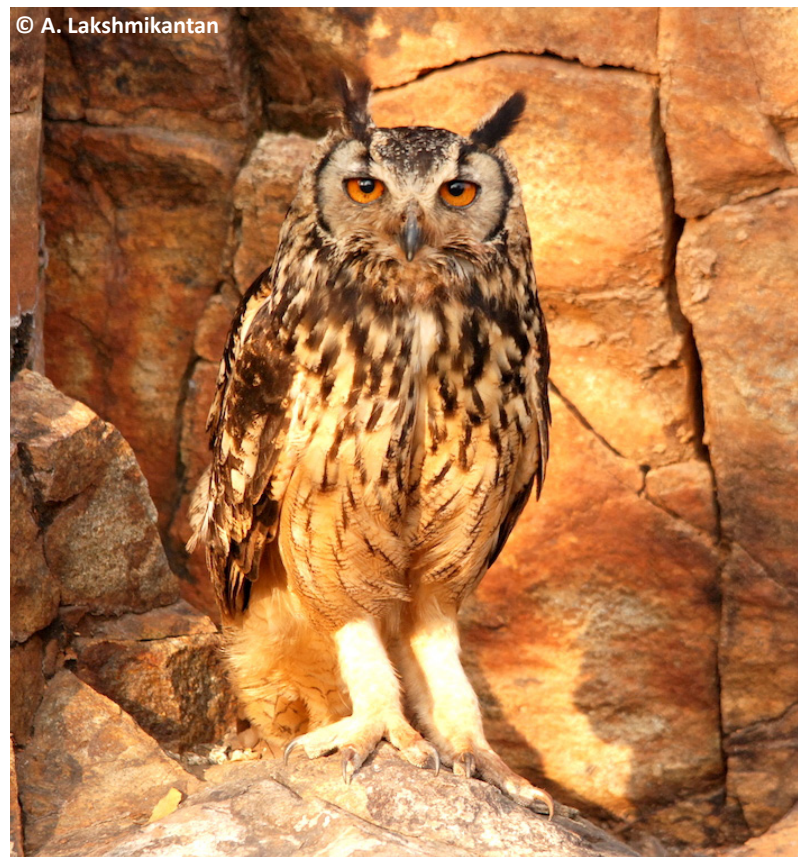

Image 9. Male parent at Vigilance Site 3. The feathers are a bit ruffled due to the photographer's approach (01 February 2011).

to deliver prey to the nest/close vicinity of site for the consumption of female and young. The number of prey deliveries was also noted and this has been presented in parenthesis.

4) Out of sight of nest region: The activity behaviour may be implied to be the time the male flew away from its perch to the time it delivered prey to the nest site.

Behavioural traits concerning agnostic displays were not detailed since these were not observed under natural conditions and occurred only when observers approached the nest on the three occasions when we were obliged to - we have mentioned it under the heading 'disturbed at nest' since details of interspecific intimidation of humans by Bubo bengalensis has been elucidated upon earlier (Ramanujam 2004, 2007, 2010).

I would like to stress that since the sample size is small and preliminary in nature, one cannot make claims or suggestions about behavioral patterns.

\section{Prey}

Over the last couple of decades the pellet analysis method (e.g., Errington 1930, 1932) has been shown to be unsatisfactory in dealing with raptor dietary studies (Rosenberg \& Cooper 1990; Simmons et al. 1991; Marchesi \& Pedrini 2002) and direct observation was the method suggested to overcome the bias (Penteriani et. al. 2002). A total of 45 prey items, all mammals, were 
Table 1. Overall activity patterns and percentage of time spent on each behavioural trait

\begin{tabular}{|c|c|c|c|c|}
\hline & Subject & Sno & Behavioural traits & $\%$ \\
\hline \multirow{10}{*}{1} & \multirow{10}{*}{$\begin{array}{l}\text { In the } \\
\text { reproductive } \\
\text { female }\end{array}$} & 1 & Incubation & 36.31 \\
\hline & & 2 & Brooding & 14.28 \\
\hline & & 3 & Vigilance & 27.09 \\
\hline & & 4 & Comfort movements & 0.45 \\
\hline & & 5 & Out of sight & 20.97 \\
\hline & & 6 & Feeding & 0.02 \\
\hline & & 7 & Pellet regurgitation & 0.02 \\
\hline & & 8 & Feeding young & 0.22 \\
\hline & & 9 & Prey delivery & 0.02 \\
\hline & & 10 & Disturbed at nest & 0.62 \\
\hline \multirow{5}{*}{2} & \multirow{5}{*}{$\begin{array}{l}\text { In the young } \\
\text { (mean \%) }\end{array}$} & 1 & Resting & 90.58 \\
\hline & & 2 & Moving & 8.51 \\
\hline & & 3 & Feeding & 0.27 \\
\hline & & 4 & Pellet regurgitation & 0.23 \\
\hline & & 5 & Flapping & 0.27 \\
\hline \multirow{6}{*}{3} & \multirow{6}{*}{$\begin{array}{l}\text { In the } \\
\text { reproductive } \\
\text { male }\end{array}$} & 1 & Vigilance at Site 1 & 48.3 \\
\hline & & 2 & Vigilance at Site 2 & 7.72 \\
\hline & & 3 & Vigilance at Site 3 & 9.36 \\
\hline & & 4 & Comfort movements & 0.66 \\
\hline & & 5 & Prey delivery & 0.04 \\
\hline & & 6 & Out of sight & 33.92 \\
\hline
\end{tabular}

delivered to the nest during our tenure and these were identified to the best of our ability. Pellets could not be collected as many of them ended up in the water since the owls nested in disused water filled mines and we could not access the actual nest site due to legal restrictions. From direct observations, the diet was found to include Lesser Bandicoot Rat Bandicota bengalensis and Tree Rat Rattus rattus and that comprised the basic food (> 20\%), constant food (5-20\%) was the Indian Gerbille Tatera indica, medium sized rodents and leverets of the Blacknaped Hare Lepus nigricollis, whereas the Indian House Shrew Suncus murinus, Soft-furred Field Rat Millardia meltada and Mice Mus spp. were supplementary food (1-5\%). It was also interesting to note that the male did most of the hunting while under observation - it delivered 36 prey items in 17 days (an average of $2.11 \%$ per day) out of which 28 were delivered after the young hatched (2.33\%). Under observation the female delivered only nine items in seven days (an average of $1.28 \%$ ).

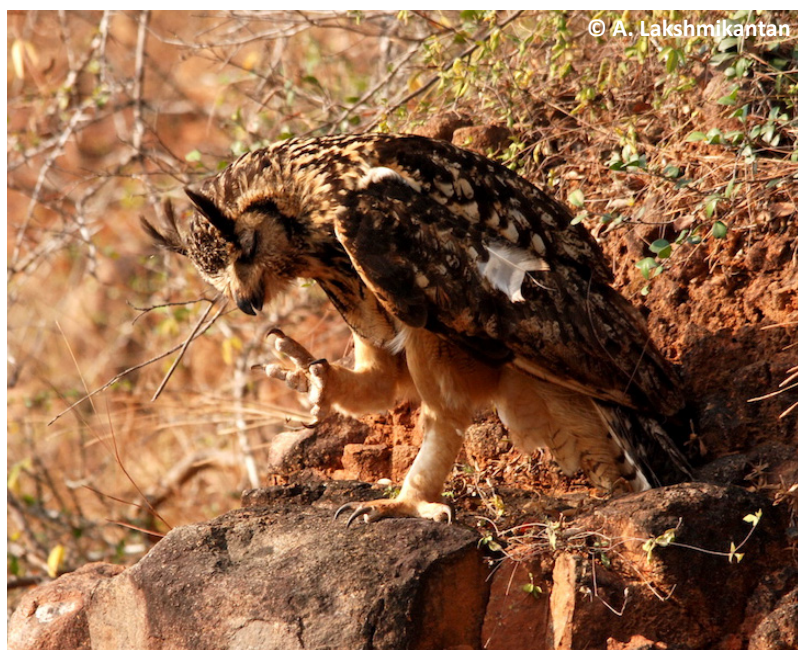

Image 11. Head scratching by female at its vigilance site (12 February 2011).

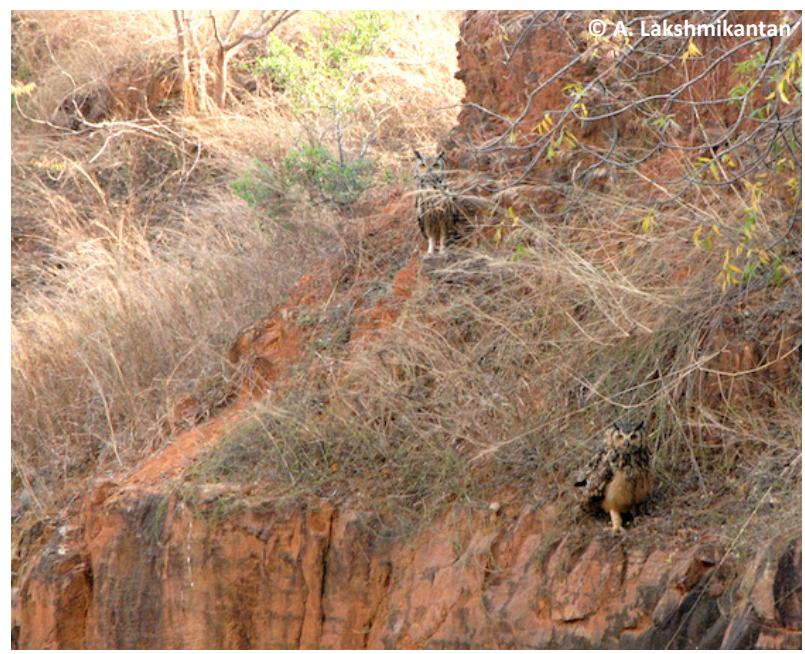

Image 12. Once the young had branched out and spread away from one another the parents too ranged widely and were difficult to spot. This photograph taken on 08 March 2011 shows both male and female - the male is at the top and the female is below. Reverse sexual diomorphism is evident.

\section{Discussion}

These studies, however preliminary in nature, provide some hypothesis concerning life history characteristics that are currently lacking for nocturnal species of owls. Though the sample size was very small and it was not possible to draw absolute conclusions, the study did throw some light on some facets of behavioural trends of the subjects during the breeding season. Some notable observations suggest that in the female its primary role was the care of its eggs and young - the combined incubation and brood time was $50.59 \%$, though at a later stage, once the young did not 
need personalized attention at the nest it too took up vigilance duties. In the male, the main function was defense of the nest and its occupants. This prompted the male to remain in the vicinity of the nest and the young for extended periods and its combined period of vigilance was $63.38 \%$ (over half its time). The reluctance of the male to vacate its vigilance sites, even when molested by crows and approached by humans, makes this pattern an interesting field technique to find the nesting site of the species. During this survey we were not attacked by the male, but in another study I have been (Ramanujam 2004) and this has been borne out by studies on other species of owls (Wiklund \& Stigh 1983; Wallin 1987; Sproat \& Grey 1993). In the young, up to the age of approximately 37 days, the prime objective was to remain motionless relying on their cryptic plumage for camouflage and they spent $90.58 \%$ resting. It is possible from non-regular sightings of nestlings at later date, they continued to use their cryptic colouration and immobility for defense.

As concerns other behaviour patterns it is too early to interpret them without a larger data set but there is hope that in future with more field biologists working on time budgets a pattern may emerge that could impinge upon the conservation biology of the species.

In conclusion I wish to state that this is a preliminary study of breeding Bubo bengalensis and in future other studies should be carried out in as many habitats as possible so that the time allotment for various activities on a daily, monthly and seasonal basis can be collated and a statistically and hypothetically valid trend elucidated. More ethograms in relation to life cycles are the need of the hour so that we can expand our information on the patterns and changes in behaviour of this taxon.

\section{REFERENCES}

Anonymous (2009). Nanmangalam Reserve Forest - A little known biodiversity reserve of Chennai. Tamil Nadu Forest Department (Research Wing), 16pp.

Asokan, S. \& A.M.S. Ali (2010). Time activity budget of White-breasted Kingfisher Halcyon smyrensis in Cauvery Delta Region, Tamil Nadu, India. Advances in Biological Research 4: 288-291.

Aumann, T. (2001). Habitat use, temporal activity patterns and foraging behavior of raptors in the south-west of the Northern Territory, Australia. Wildlife Research 28: 365 - 378.

Bosakowski, T. (1989). Observations on the evening departure and activity of wintering Short-eared Owls in new jersey. Journal of Raptor Research 23: 162-166.

Cain, S.L. (2010). Time budgets and behavior of nesting Bald Eagles. In: Wright, B.A. \& P. Schempf (eds.). Bald Eagles in Alaska. Hancock House Publishers, WA, USA, 436pp.

Chipman, E.D. (2006). Behavioral ecology of Western Burrowing Owls (Athene cunicularia hypugaea) in northwestern Texas. MSc thesis, Texas Tech University, 99pp.
Collopy, M.W. \& T.C. Edwards (1989). Territory size, activity budget, and role of undulating flight in nesting golden eagles. Journal of Field Ornithology 60: 45-51.

Delaney, D.K. \& T.G. Grubb (1999). Activity patterns of nesting Mexican spotted owls. Condor 101: 42-49.

Errington, P.L. (1930). The pellet analysis method of raptor food habits study. Condor 32: 292-296.

Errington, P.L. (1932). Technique of raptor food habits study. Condor 34: 75-86.

Evers, D.C. (1994). Activity budgets of a marked Common Loon (Gavia immer) nesting population. Hydrobiology 279 \& 280: 415-420.

Fischer, D.L. (1986). Daily activity patterns and habitat use of coexisting Accipiter Hawks in Utah. PhD dissertation, Brigham Young University, Provo, UT, 70pp.

Hamilton, A.J., I.R. Taylor \& G. Hepworth (2002). Activity budgets of waterfowl (Anatidae) on a waste stabilization pond. Emu 102: 171-179.

Haug, E.A. \& L.W. Oliphant (1990). Movements, activity patterns, and habitat use of Burrowing Owls in Saskatchewan. Journal of Wildlife Management 54: 27-35.

Jimenez, J.E. \& F.M. Jasic (1989). Behavioral ecology of Grey eaglebuzzards, Geranoaetus melanoleucus, in central Chile. The Condor 91: 913-921.

Johnson, D.H. (1999). The insignificance of statistical significance testing. Journal of Wildlife Management 63: 763-772.

Jonsson, J.E. \& A.D. Afton (2006). Different time and energy budgets of Lesser Snow Geese in nice-praries and coastal marshes in southwest Louisiana. Waterbirds 29: 451-458.

Krivtsov, S. (1988). Daily time and energy budgets in Snowy Owls at low density of small rodents, pp. 34-39. In: Ecological Energetics of Animals. Sverdlovsk, Ural Branch of the Academy of Sciences of the USSR.

Kumar, T.S. (1985). The Life History of the Spotted Owlet (Athene brama brama Temminck) in Andhra Pradesh. Monograph of the Raptor Research Centre, Hyderabad, 241pp.

Kurup, G.U. \& A. Kumar (1993). Time Budget and Activity Pattern of the Lion-tailed Macaque (Macaca silenus). International Journal of Primatology 14: 27-39.

LaFever, D.H., K.F. LaFever, D.C. Catlin \& D.K. Rosenberg (2008) Diurnal time budget of Burrowing Owls in a resident population during the non-breeding season. The Southwestern Naturalist, $18 \mathrm{pp}$.

Madders, M. \& D. Whitfeld (2006). Upland raptors and assessment of wind farm impacts. Ibis 148: 43-56.

Mahabal, A. (1991). Activity time budget of the Indian Myna Acridotheres tristis (Linnaeus) during the breeding season. Journal of the Bombay Natural History Society 90: 96-97.

Marchesi, L. \& P. Pedrini (2002). Biases associated with diet study methods in the Eurasian Eagle Owl. Journal of Raptor Research 36: 11-16.

Natarajan, V. (1991). Time budgeting by the Southern Crow Pheasant (Centropus sinensis) at Point Calimere, Tamil Nadu. Journal of the Bombay Natural History Society 90: 92-95.

Pande, S. \& N. Dahanukar (2011). Ecological effects on morphometric development of the Indian Eagle Owl Bubo bengalensis. Journal of Threatened Taxa 3(4): 1677-1685; http://dx.doi.org/10.11609/ JoTT.02609.1677-85

Pauls, S.L. (1998). Time activity budgets of Mottled Ducks in Louisiana in winter. Journal of Wildlife Management 52: 711-718.

Penteriani, V., M. Gallardo \& P. Roche (2002). Landscape structure and food supply affect Eagle Owl (Bubo bubo) density and breeding performance: a case of intra-population heterogeneity. Journal of the Zoological Society of London 257: 365-372.

Penteriani, V., A. Kuparinen, M. del M. Delgado \& R. Lourenco (2011). Individual status, foraging effort and need for conspicuousness shape behavioural responses of a predator to moon phases. Journal of Animal Behaviour 82(2): 413-420; http://dx.doi.org/10.1016/j. anbehav.2011.05.027

Plumpton, D.L. \& R.S. Lutz (1993). Influence of vehicular traffic on time 
budgets of nesting burrowing owls. Journal of Wildlife Management 57: 612-616.

Potapov, E. \& R. Sale (2012). The Snowy Owl. T. \& A.D. Poyser, London, $336 \mathrm{pp}$.

Ramachandran, N.K. (1998). Activity patterns and time budgets of the Pheasant-tailed (Hydrophasianus chirugus) and Bronzewinged (Metopidius indicus) Jacanas. Journal of the Bombay Natural History Society 93: 234-245.

Ramanujam, M.E. (2004). Inter-specific intimidatory behaviour of adult Indian Eagle Owls Bubo bengalensis (Franklin) in defence of their nestlings. Zoos' Print Journal 19(2): 1343-1345; http://dx.doi. org/10.11609/JoTT.ZPJ.19.2.1343-5

Ramanujam, M.E. (2007). A catalogue of auditory and visual communicatory traits in the Indian Eagle Owl Bubo bengalensis (Franklin, 1831). Zoos' Print Journal 22(8): 2771-2776; http:// dx.doi.org/10.11609/JoTT.ZPJ.1572.2771-6

Ramanujam, M.E. (2010). Some observations on the spread-winged agnostic displays of the Indian Eagle Owl Bubo bengalensis (Franklin, 1831). Journal of Threatened Taxa 2(9): 1147-1152; http://dx.doi. org/10.11609/JoTT.o2249.1147-52

Ramanujam, M.E. \& T. Murugavel (2009). A preliminary report on the development of young Indian Eagle Owl Bubo bengalensis (Franklin, 1831) in and around Puducherry, southern India. Journal of Threatened Taxa 1(10): 519-524; http://dx.doi.org/10.11609/ JoTT.01762.519-24

Ramanujam, M.E. \& B. Verzhutskii (2004). On the prey of the Spotted Owlet Athene brama (Temminck) in a forested ravine in Auroville, Pondicherry. Zoos' Print Journal 19(10):1654-1655; http://dx.doi. org/10.11609/JoTT.ZPJ.1093a.1654-5

Reinecke, K.J. (1979). Feeding ecology and development of juvenile black ducks in Maine. The Auk 96: 737-745.
Sheilds, G.F. (1969). Activity cycles of snowy owls at Barrow, Alaska. Murrelet 50: 14-16.

Simmons, R.E., D.M. Avery \& G. Avery (1991). Biases in diets determined from pellets and remains: correction factors for a mammal and bird-eating raptor. Journal of Raptor Research 25: 63-67.

Sivakumaran, N. \& K. Thiyagesan (2003). Population, diurnal activity patterns and feeding ecology of the Indian Roller (Coracias benghalensis). Zoos' Print Journal 18(5): 1091-1095; http://dx.doi. org/10.11609/JoTT.ZPJ.18.5.1091-5

Sovern, S.G., E.D. Forsman \& B.L. Biswell (1994). Diurnal behaviour of the Spotted Owl in Washington. Condor 96: 200-202.

Sproat, T.M. \& G. Ritchison (1993). The nest defence behavior of Eastern Screech Owls: effects of nest stage, sex, nest type and predator location. The Condor 95: 288-296.

Verzhutskii, B. \& M.E. Ramanujam (2002). On the prey of the Collared Scops Owl Otus bakkamoena (Pennant) at Auroville, Pondicherry. Zoos' Print Journal 17(11): 939-940; http://dx.doi.org/10.11609/ JoTT.ZPJ.17.11.939-40

Wallin, K. (1987). Defence as parental care in Tawny Owls (Strix aluco). Behaviour 102: 213-230.

Watson, J.W., M.G. Garrett \& R.G. Anthony (1991). Foraging ecology of bald eagles in the Columbia River estuary. Journal of Wildlife Management 55: 492-499.

Wiklund, C.G. \& J. Stigh (1983). Nest defence and evolution of reversed sexual diomorphism in Snowy Owls Nyctea scandaica. Ornis Scandinavica 14: 58-62.

Yoccov, N.G. (1991). Use, overuse, and misuse of significance tests in evolutionary biology and ecology. Bulletin Ecological Society of America 72: 106-111. 